\title{
Diaphragm Damage of Precast Concrete T-Shape Girder Bridge: Analysis and Strengthening
}

\author{
Yanwei Niu ${ }^{1,2, *}$, Bangjun $\mathrm{Liu}^{3}$, Yu Zhao ${ }^{1}$, Shuai Rong ${ }^{1}$ and Pingming Huang ${ }^{4}$ \\ ${ }^{I}$ School of Highway, Chang'an University, Xi'an, China \\ ${ }^{2}$ Loess Region Key Laboratory of Transportation Ministry, Taiyuan, China \\ ${ }^{3}$ TYLI Engineering Consulting \\ ${ }^{4}$ Middle of South $2^{\text {nd }}$ Ring Road, Xi'an, 710064, China
}

\begin{abstract}
For advantage of economical and practical construction, precast T-shape girder bridge is commmonly used in China. In recent years, damage of diaphragm became a serious problem in operation and maintenance. In this study, based on finite element (FE) analysis of an actual bridge, stress distribution and failure process of diaphragm is demonstrated. The result shows that the stress of middle diaphragms started to beyond the limit firstly, under heavey load of 1.5 times equivalent Grade highway-I live load. Then, method of Double-K brace to strengthen the transveral connnection of the exist bridges is proposed and applied on background bridge. Based on the field test, tensile stress of diaphragms concrete reduced $69.4 \%$ when Double-K brace were adopted, and the lateral integrity of precast T-beam bridge could be improved effectively.
\end{abstract}

Keywords: Concrete bridge, T-shape girder, diaphragm, damage, strengthening.

\section{INTRODUCTION}

Precast continuous bridge has the advantages of constructs conveniently and low cost, thus become one of the dominant bridge types for medium and small span bridges in China. As a main connection component along transverse direction, diaphragms connect girders as an integrity to bear horizontal forces and live load. In recent years, damage of diaphagms arise gradually, sometimes even cause collapse[1]. Many bridges need further inspection and rehabilitation [2 3]. LIANG concluded the stress of diaphragm in the midspan is the most unfavorable [4]. PENG studied the diaphragms stress after pasting steel plate based on FE analysis [5]. And lateral prestress tendon was used to ameliorate the stress of diaphragm [6]. For highway under heavey vehicle load, the process of diaphragm damage needs further study. The research background of this study is highway from Yang-quan to Zuo-quan in Shanxi Provce, with heavey coal transportation. A three-span continuous precast T-Shape girder bridge is simulated by FE model to illustrate the damage process and failure of diapgragms under different grade of live load. After comparision, a strengthening method by spacial double-K shape brace is proposed and applied to enhance the transverse connection and decrease the tensile stress of exsiting diaphragms.

*Address correspondence to this author at the School of Highway, Chang'an University, Xi'an, China; Tel: +86-(029)-82336336;

E-mail: niuyanwei@chd.edu.cn

\section{STRESS ANALYSIS OF DIAPHRAGM DAMAGE}

\subsection{Background Bridge}

The span length of background bridge is $40 \mathrm{~m}$, composed of 5 T-Shape precaset prestressed concrete girder, with 7 diaphragms along longitudinal direction: 2 end diaphragms and 5 middle diaphragms. The height of main girder is $2.5 \mathrm{~m}$ and $1.7 \mathrm{~m}$ widith of top flange (Fig. 1) with $70 \mathrm{~cm}$ width castin-place joints. The thickness of diaphragm is $20 \mathrm{~cm}$ in midspan diaphragms and $60 \mathrm{~cm}$ near the bearings. Overload trucks go through the bridge is relatively common during daily operation. To void crack apperance in the diaphragms is of great caution to stakeholder.

\subsection{Damage Process}

Live load of Chinese Code [7] is combination of a uniform distribution load and concentrate load. In order to compared the results of FE method with truck load in daily operation, Code load is transformed to several concentrate load with equivalent internal forces: sagging moment of mid-span keeps constant before and after the conversion. The vehicle load contains 2 trucks: 12 concentrated forces in total, and the rear axle loads are $250 \mathrm{kN}$, the front axle loads are $125 \mathrm{kN}$. Adopting 4 load cases to observe the stress process of diaphragms with the increasing load, which is dead load (DL) plus live load to 2 times of Grade Highway-I live load (LL) of Chinese Code.

With the truck load increasing, the diaphragms of midspan is most sensitive. Under "dead load+live load", the 


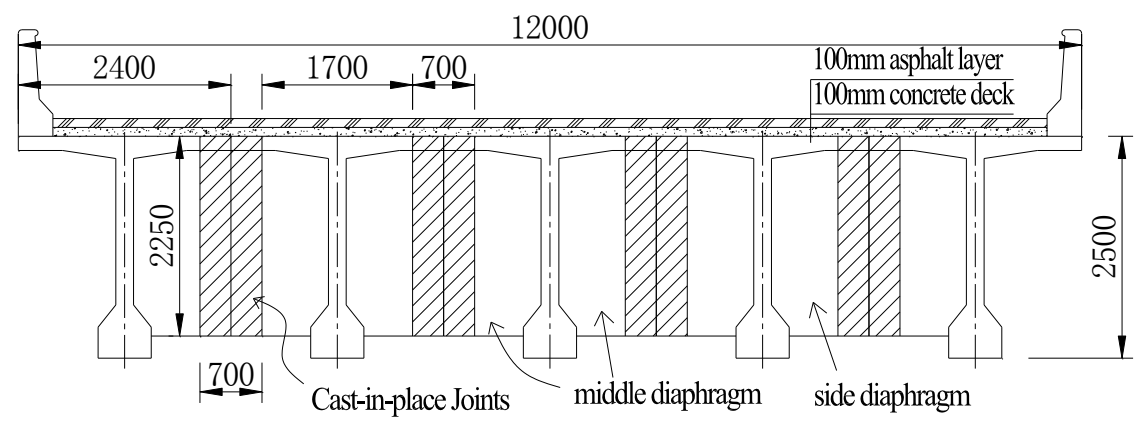

Fig. (1). Cross-section of background bridge.

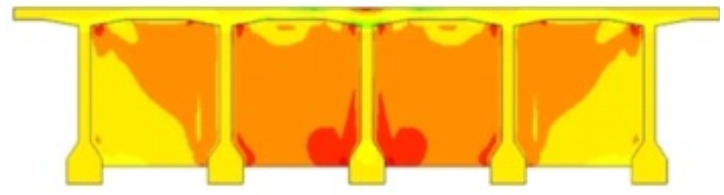

a. Case I: Dead load + Live load

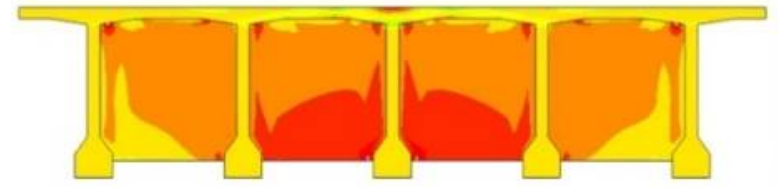

b. Case II: Dead load $+1.25^{*}$ Live load

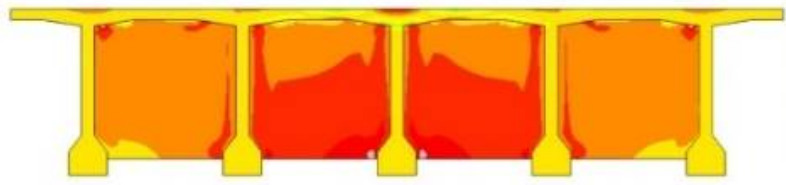

c. Case III: Dead load $+1.5 *$ live load

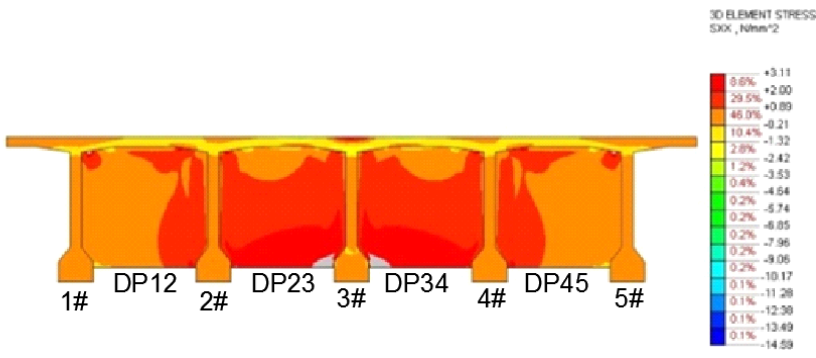

d. Case IV: Dead load $+2 *$ live load

Fig. (2). Stress of concrete under different live load intensity.

upper fiber of side diaphragm (DP12 and DP45 in Fig. 2) was tensile, bottom fiber of side diaphragms was compressed; while both upper and bottom fiber of middle diaphragms (DP23 and DP34) were tensile. The maximum tension stress was $1.07 \mathrm{MPa}$, near the lower part of T-Shape girder.

Under " $1.25 *$ live load", the stress side diaphragms changes a little, and the bottom fiber of becomes tensile, the tension stress is $0.085 \mathrm{MPa}$. While the tension stress of bot- tom fiber of middle diaphragms incresed to $1.475 \mathrm{MPa}$, which is greater than design value of concrete (C50) tension strength. Concrete near the lower part of $\mathrm{T}$-shape girder begin to crack.

Under "1. $5 *$ live load", tension stress of all bottom part of middle diaphragms increased to $1.893 \mathrm{MPa}$; cracks between middle diaphragms and T-Shape girder keeps extending upward. 


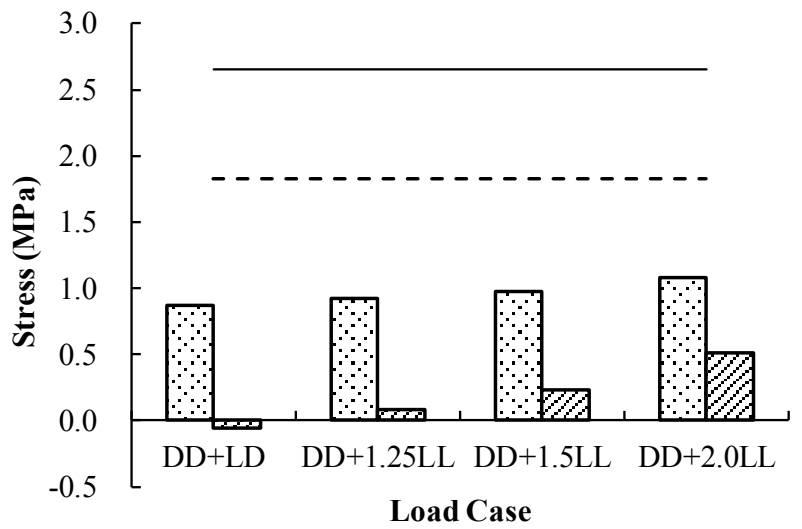

a. side diaphragm

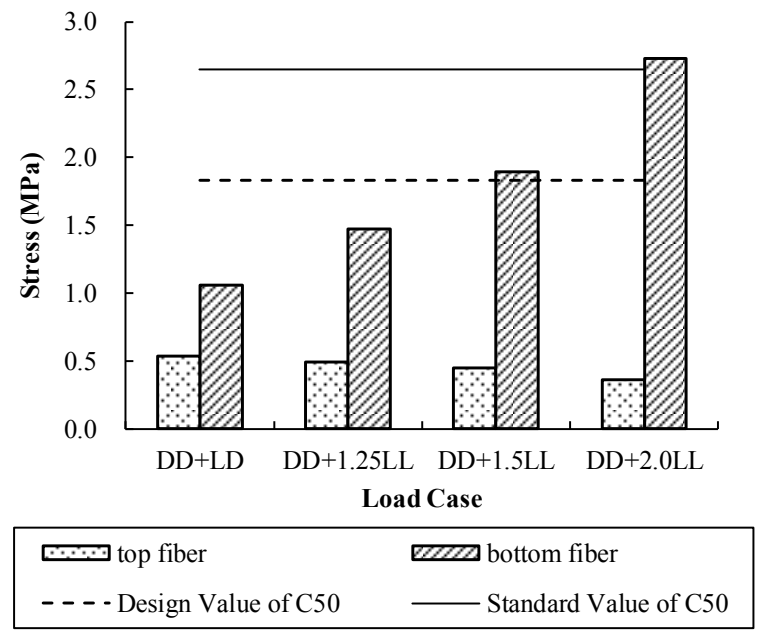

b. middle diaphragm

Fig. (3). Concrete stress of mid-span diaphragm under different live load.

When live load attend " $2 *$ live load", the stress of middle diaphragms totally over tension strength of concrete, and the middle diaphragms crack and damage.

To sum up, with the increasing of truck load, damage of precast continuous T-shape girder bridge started from zones between middle diaphragms and lower part of T-shape girder, and keep extending upward. Until the upper fiber of middle diaphragms totally craked, the diaphragms was damaged (Fig. 3), and the integrity of the bridge droped sharply.

\section{TRANSVERSE STRENGTHENING OF PRECAST T-SHAPE GIRDER BRIDGE}

Based on the damage process of diaphragms, spacial steel braces were adopted to behave together with concrete diaphragms. There are 3 kinds of space braces considered: straight brace, cross brace and $\mathrm{K}$ brace. As shown in Fig. (4), in both lateral and vertical direction K-shape brace was used to form a reliable and integrate structure, so it is named for "spacial double-K brace". The eccentric distance of space straight brace is small, so the efficiency is smaller than cross brace and K-shape brace. Further more, the installation and welding of space double-K brace is more convenient than cross brace, so finally spacial double-K brace was adopted. For construction convenient, spacial braces were set at the 1/3L and 2/3L (Fig. 5) span of backgroud bridge.

\subsection{Fabrication and Installation of Double-K Brace}

The embedded members were made of Q235 steel, and welded to the bars of main girder in advance, then connected with diagonal braces, tranverse braces and horizontal braces through high-strength bolts and steel plates into integrity.

Size of members was shown in Table 1, and all the angle steels and steel plates were sand-blasted and anti-rusted before installed. 


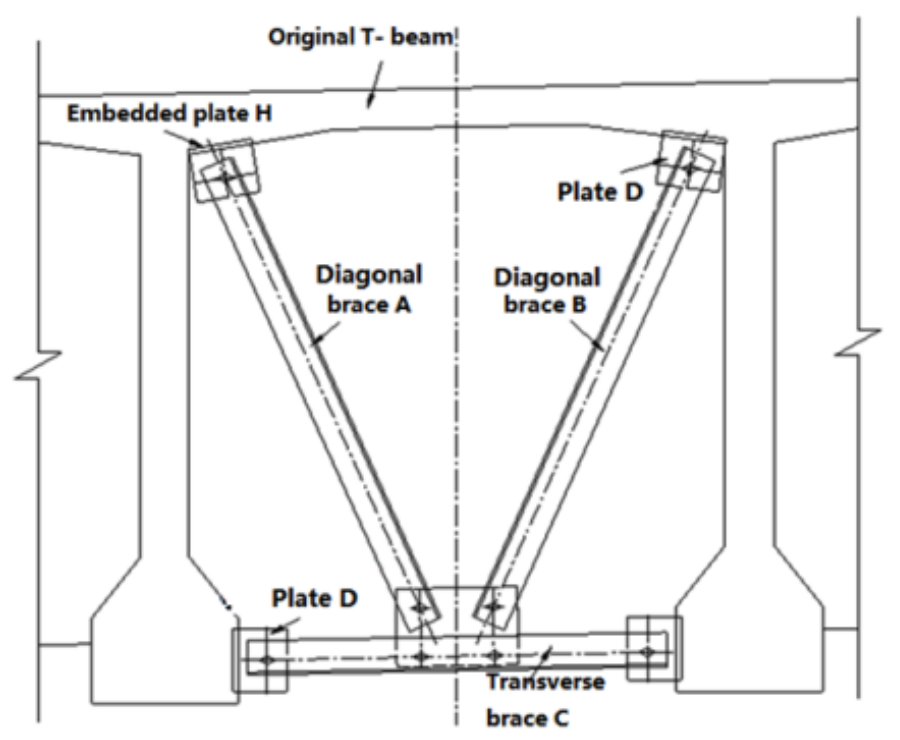

a. elevation

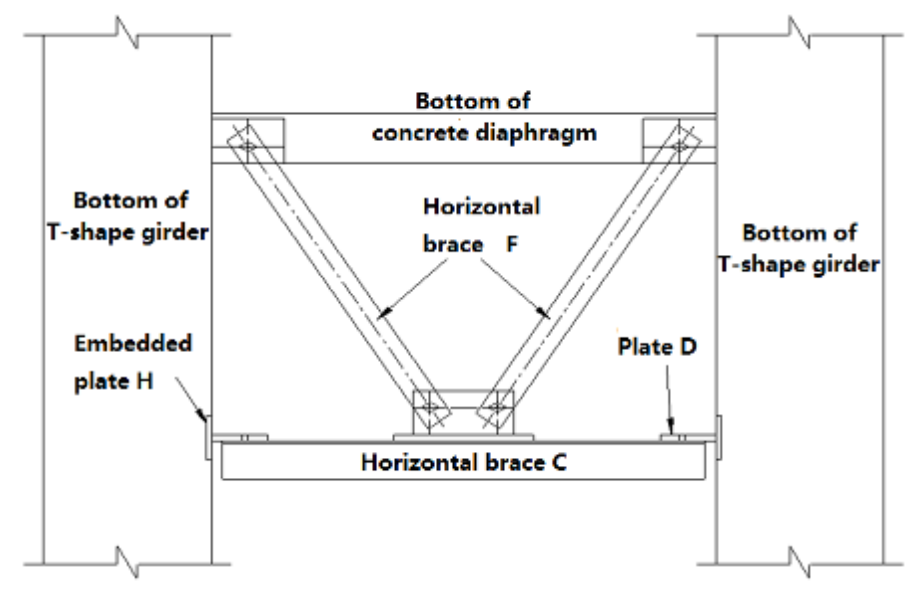

b. plan

Fig. (4). Design of spacial Double-K shape brace.

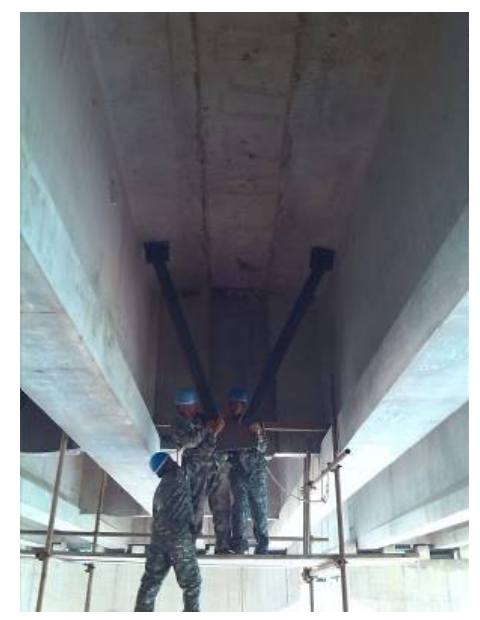

a. Install of diagonal brace

Fig. (5). Contd... 


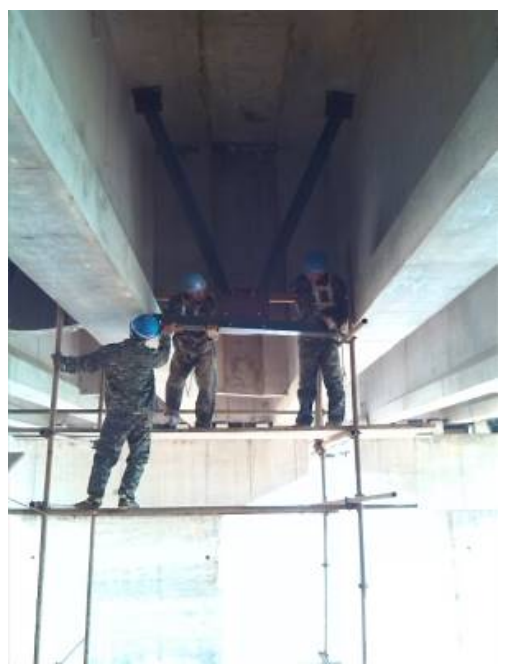

b. Install of transverse brace

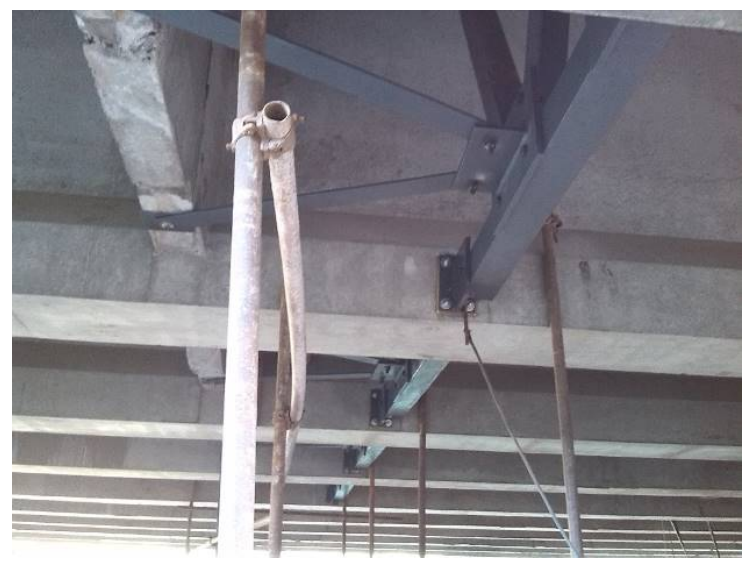

c. Final horizontal brace install

Fig. (5). Install of double-K brace.

Table 1. Member size of double-K brace.

\begin{tabular}{|c|c|}
\hline Member & Size(mm) \\
\hline \hline diagonal brace A, B & L $140 \times 10$ \\
\hline transverse brace C & L $140 \times 10$ \\
\hline horizontal brace F & $100 \times 1263 \times 10$ \\
\hline Bolts & M20 \\
\hline
\end{tabular}

To install the double- $\mathrm{K}$ brace, the diagonal brace is connect to embeded plate of flange first, then install central connection plate and transverse brace. Finally, lateral braces installed to connect original concrete diaphragm. Process of installation is shown in Fig. (5).

\subsection{FE Analysis of Strengthening Method}

FE solid model was adopted to analyze the stress of Tshape girder diaphragms with and without spacial braces, to study the structural performance improvement. FE solid model contains 125067 elements. Prestressing tendon and wild reinforcement were simulated by truss elements, and the connection between bars and concrete were simulated by interface elements. Spacial double-K braces were simulated by solid elements (part of model is shown in Fig. 6).

To attain the worst condition, vehicle is load at the section $16 \mathrm{~m}$ (about $0.4 \mathrm{~L}$ ) away from the expansion joint of side span abutment. As shown in Fig. (7), four trucks with net 


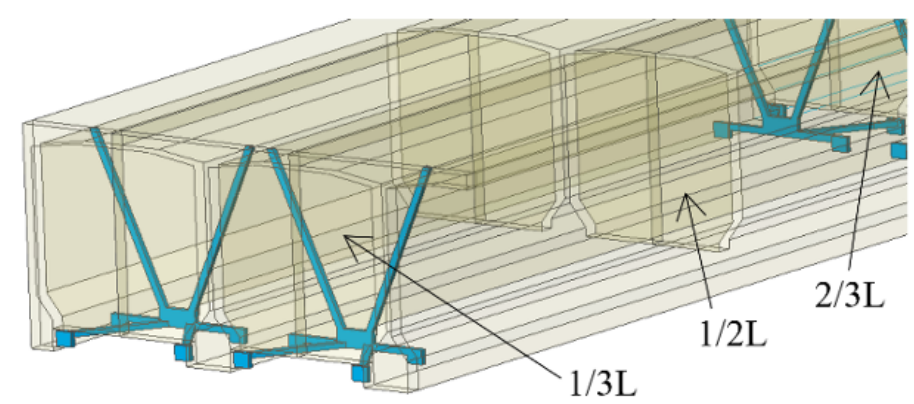

Fig. (6). FE model of bridge with double-K brace (partial view).

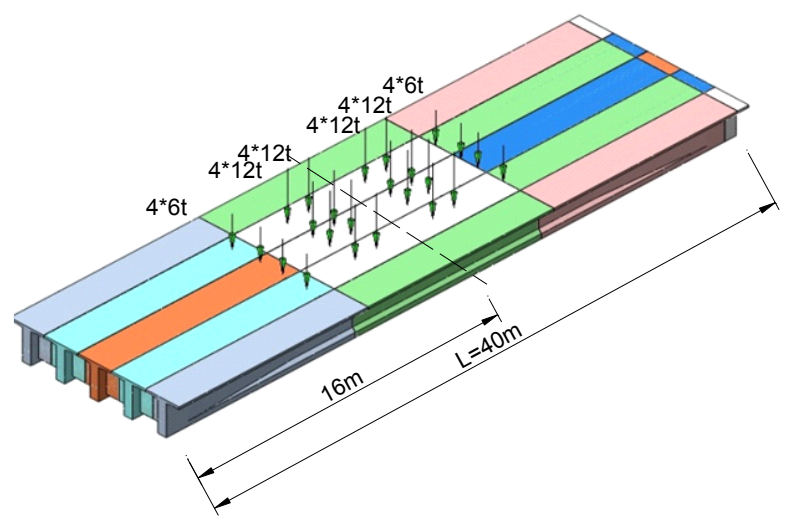

a. Axis load

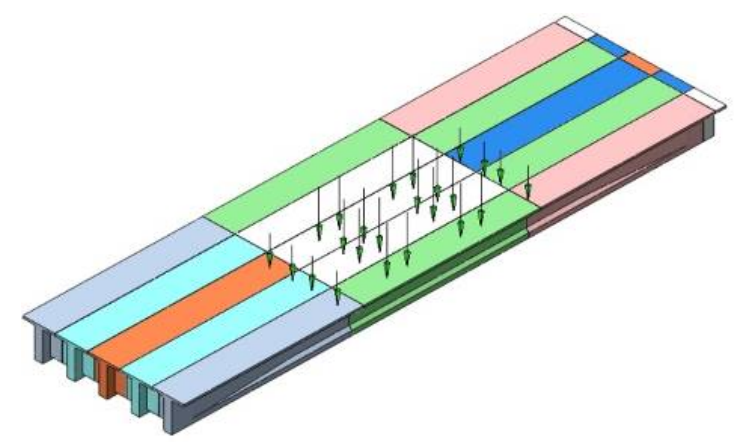

b. Eccentric load

Fig. (7). FE model under test truck load.

weight $30 \mathrm{t}$ each is loading at both axis and eccentric from the bridge central line.

There are 4 load case considered as shown in following table:

As Fig. (8) shown, with spacial double-K braces strengthening, the tension stress of bottom fiber of diaphragms at $1 / 3 \mathrm{~L}$ span reduced by $17.1 \%$ under symmetric loading and $19.6 \%$ under eccentric loading. And the maximum tension stress of bottom fiber of diaphragms at midspan $(1 / 2 \mathrm{~L})$ decreased by $8.3 \%$, and $6.9 \%$ under eccentric loading. For stress of double-K braces, the maximum of was about $8.95 \mathrm{MPa}$ under symmetric loading and 7.66MPa under eccentric loading.

\subsection{Experiment of Background Bridge}

For different driving direction, background includes two separate bridges: Right-bridge from Yang Quan city to Zuo Quan county and Left-bridge along the opposite direction. To verify the strengthening effect, double-K baces were installed on the right-bridge and left-bridge keeps the original design (Fig. 9). The truck load and postion is accordance to above load case I to IV in Table 2 . Strain gauges were set at 


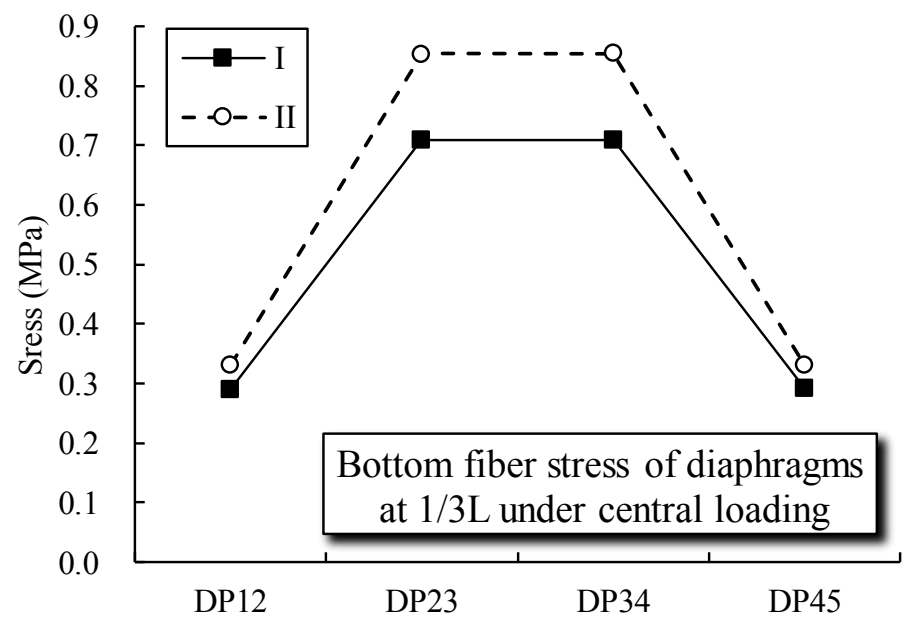

a. Diaphragms at $1 / 3 \mathrm{~L}$ under central loading

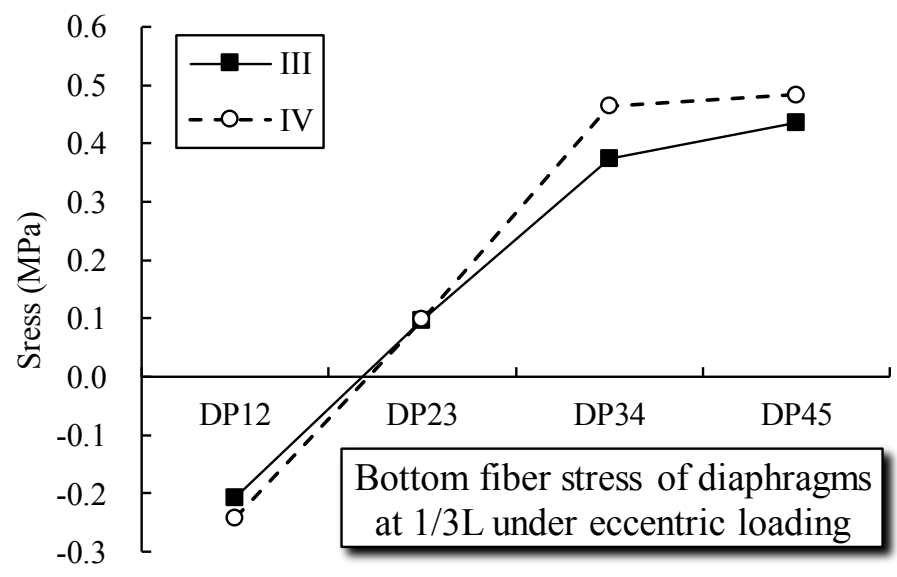

b. Diaphragms at $1 / 3 \mathrm{~L}$ under eccentric loading

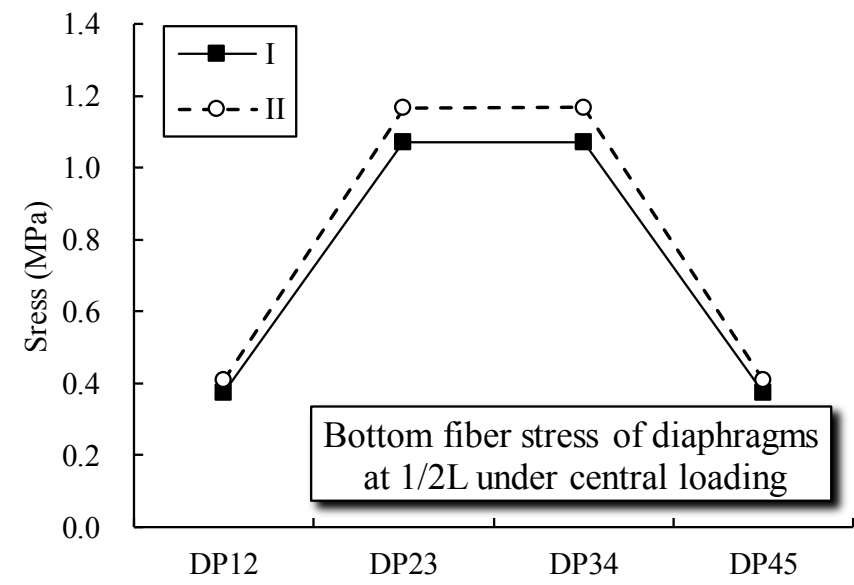

c. Diaphragms at $1 / 2 \mathrm{~L}$ under axis loading

Fig. (8). Contd... 


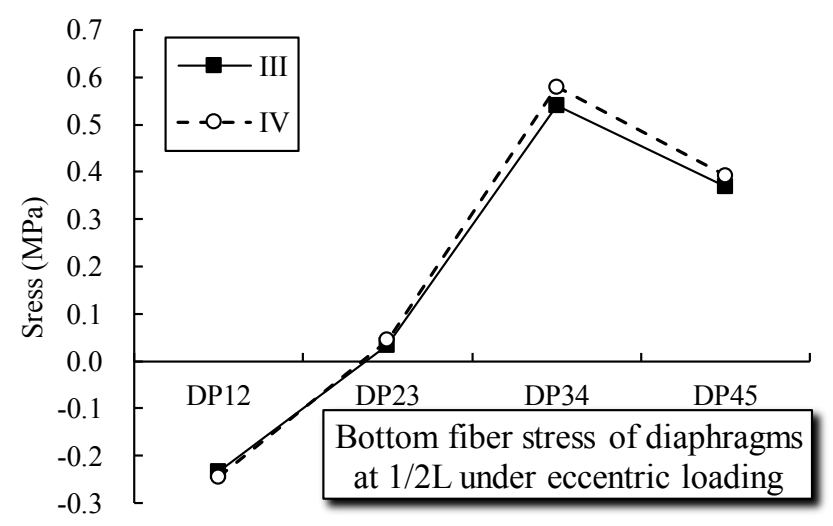

d. Diaphragms at $1 / 2 \mathrm{~L}$ under eccentric loading

Fig. (8). Stress comparison of bottom fiber of diaphragms by FE.

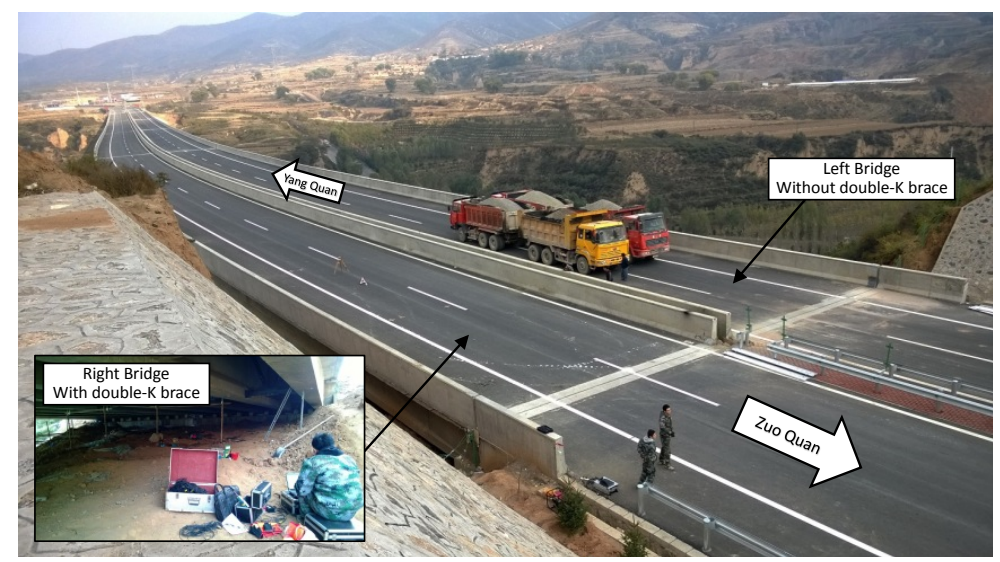

Fig. (9). Field test of background bridge.

Table 2. Load case of background bridge.

\begin{tabular}{|c|c|c|}
\hline Case No. & Load Location & With or without double-K brace \\
\hline \hline I & axis load & with \\
\hline II & axis load & without \\
\hline III & eccentric load & without \\
\hline IV & eccentric load & \\
\hline
\end{tabular}

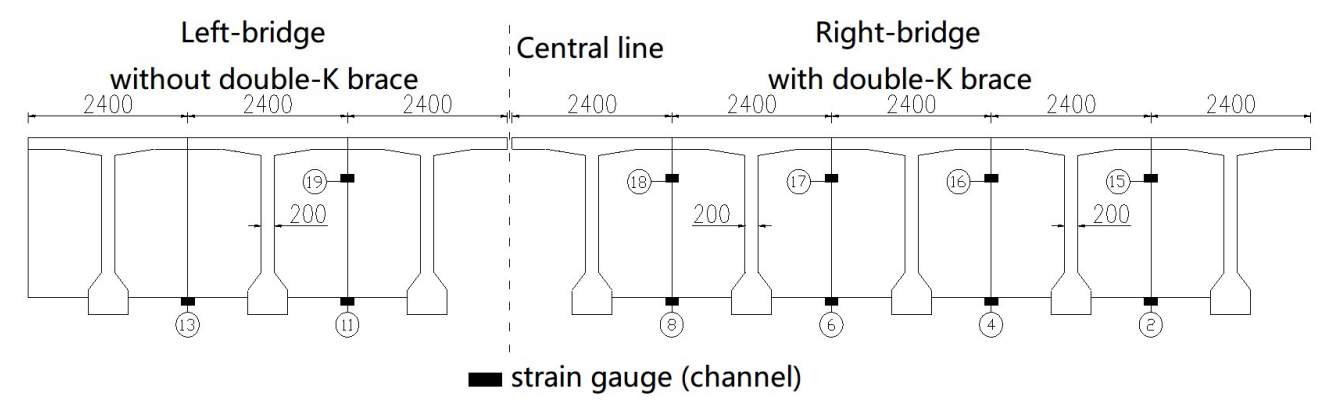

Fig. (10). Strain gauge displacement in the $1 / 3 \mathrm{~L}$ diaphragms. 


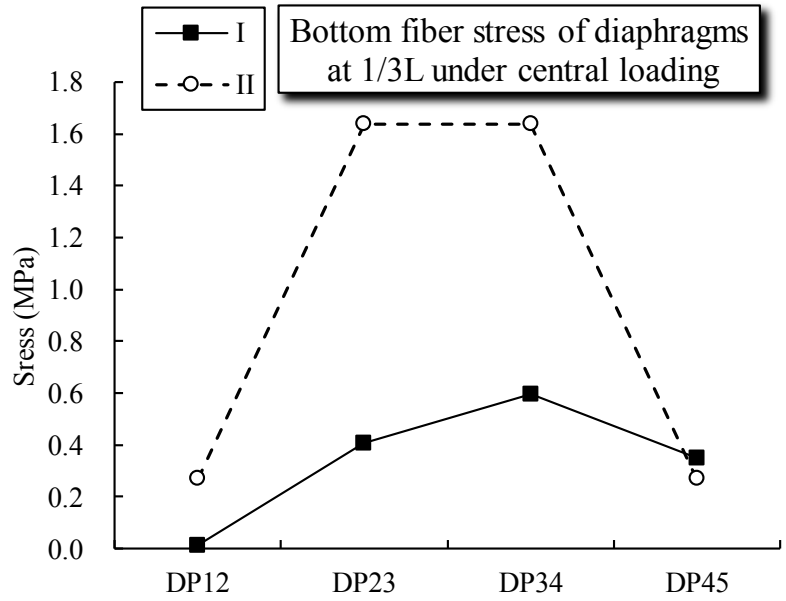

a. Diaphragms at $1 / 3 \mathrm{~L}$ under axis loading

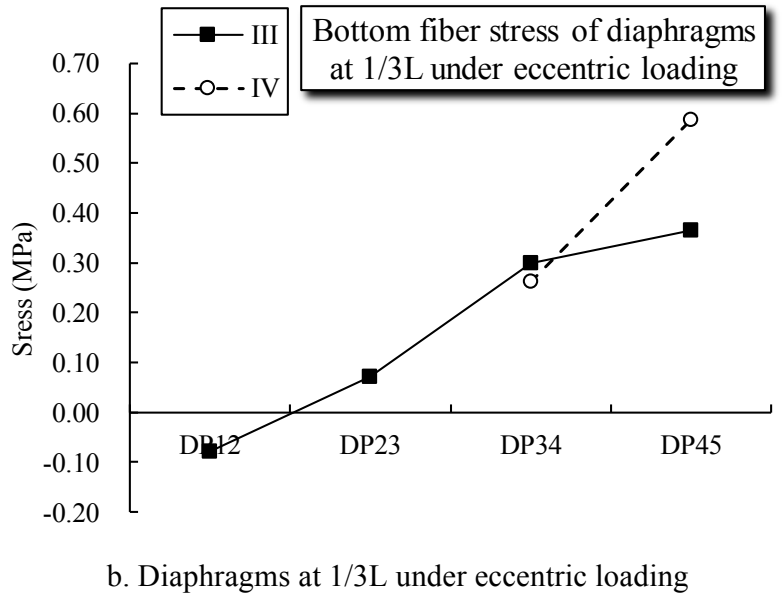

Fig. (11). Stress comparison of diaphragms by field test.

the $1 / 3 \mathrm{~L}$ diaphragms to test the stress distribution along the transverse direction. For steep terrain below the left-bridge, stress gauges were only set on the two diaphragms near the central line (Fig. 10). For the data of DP12 and DP23 in Fig. (11a) is obtained by mirroring from DP34 and DP 45 where stress gauges were set.

Result of the field test shows, under axis load case I and II, tension stress of diaphragms in right-bridge was obviously decreased compared to the right-bridge; tension stress of side diaphragms was relatively small, which was about $0.1 \mathrm{MPa}$. And for middle diaphragms (DF23, DF34), tension stress decreased from $1.64 \mathrm{MPa}$ to $0.5 \mathrm{MPa}$, reduced by $69.4 \%$.

Under eccentric loading case III and IV, stress of bottom is not as significant as axis load case; for side diaphragm DP45, stress of right-bridge is smaller than left-bridge either. The result of DP34 is close, response of both bridges is relatively small.

\section{CONCLUSION}

To analyze the damage mechanism, stress under heavy load and strengthening method of diaphragms of $\mathrm{T}$-shape multi-girder bridges is discussed in this studied, main conlusion remarks are as follow:

1. With the increasing of truck load, the tension stress of the zones between middle diaphragms and lower part of $\mathrm{T}$ shape girder first beyonds the design value of concrete tension strength, and the cracks appears. The stress of bottom fiber of middle diaphragms increases and the cracks between middle diaphragms and lower part of T-shape girder extends upward.

2. Based on FE analysis, the stress of bottom fiber of middle diaphragms would exceed the design value of concrete tension strength when truck load over 1.5 times of Code value. When the live load increased to 2 times Code value, middle diaphragms would totally crack and the bridge integrity drops sharply.

3. After the spacial double-K braces were set, the stress of critical part of diaphgrams decreases significantly. FE analysis shows that with spacial braces, the maximum tension stress of bottom fiber of diaphragms at 1/3L span reduced by $17.1 \%$ under central load and reduced by $8.3 \%$ for diaphragms at mid-span. Under eccentric loading, the maximum tension stress of bottom fiber of diaphragms at $1 / 3 \mathrm{~L}$ 
span decreased by $19.6 \%$ with space braces and reduced by $6.9 \%$ for mid-span diaphragms.

4. Field load test shows tension stress of middle diaphragms at the $1 / 3 \mathrm{~L}$ reduced by $69.4 \%$ in axis loading case. For side diaphragms under eccentric loading stress is smaller either. Strengthening method proposed is effective and practical, and can be referenced for simillar bridges especially under heavy operation loads.

\section{CONFLICT OF INTEREST}

The authors confirm that this article content has no conflicts of interest.

\section{ACKNOWLEDGEMENTS}

The authors would like to gratefully acknowledge the support from National Natural Science Foundation of PR China (51208056), Foundation of Loess Region Key Laboratory of Transportation Ministry (KLTLR-Y12-7) and Shanxi
Transportation Science and Technology Foundation (11-224).

\section{REFERENCES}

[1] http://news.163.com/11/0715/07/7902IAMU0001124J.html) 2011.

[2] Y. Liu, S.F.Ma, C.X.Zhang, "Internal force effect of T-shape girder bridge transverse diaphragm damage on whole bridge," Transportation Science \& Technology, vol. 4, pp. 38-40, 2012.

[3] F.Li, X.L.Tang, and Y.Xu, "Research of concrete T-shape girder bridge lateral connection strengthening methods," In:Proceeding of Evaluation and Strengthening of Existing bridges, Nanjing, China, pp. 91-95. 2008.

[4] Z.G.Liang, Y.Zhang, and J.L.Liu, "Damage and strengthening methods of precaset T-shape diaphragms," China Municipal Engineering, vol. 5, pp. 92-93, 2007.

[5] B.Peng, and J.Du, "Submodel method application in reinforcing cross beam of bridge," Journal of Guizhou University of Technology (Natural Science Edition), vol. 3, pp. 67-70, 2007.

[6] D.X.Ye, H.J.Yan, Slide bar application in precast T-shape girder diaphragms strengthening, Engineering and Construction, 24(6), 790-791 826 (2010).

[7] Ministry of Communication of China; General Code for Design of Highway Bridges and Culverts (JTG D60- 2004), China Communication Press; Beijing (2004).

(C) Niu et al.; Licensee Bentham Open.

This is an open access article licensed under the terms of the Creative Commons Attribution Non-Commercial License (http://creativecommons.org/licenses/by$\mathrm{nc} / 3.0 /$ ) which permits unrestricted, non-commercial use, distribution and reproduction in any medium, provided the work is properly cited. 